\title{
Uniform-Price Auctions with Adjustable Supply
}

\author{
David McAdams*
}

August 10, 2006

\begin{abstract}
In the uniform-price auction with adjustable supply, the seller decides how much to sell after receiving the bids so as to maximize its ex post profit. Given $N$ bidders and adjustable supply, all equilibria of the uniform-price auction lead to price on order $\frac{1}{N^{3}}$ below the Walrasian price. By contrast, given the usual market-clearing rule it is well-known that the uniform-price auction can lead to equilibrium prices on order $\frac{1}{N}$ below the Walrasian price.
\end{abstract}

\section{Introduction}

Uniform-price auctions are popular mechanisms to allocate multiple identical objects. For instance, in September 1998, the U.S. Treasury Department switched from its traditional

${ }^{*}$ I thank Susan Athey, Robert Wilson, participants at FERC, Maryland, Northwestern, and UC Energy Institute seminars and especially Jeremy Bulow and Paul Milgrom for very insightful comments. This research has been supported by the John Olin Foundation through a grant to the Stanford Institute for Economic Policy Research, as well as by the State Farm Companies Foundation and National Science Foundation grant SES-0241468. I gratefully acknowledge the Federal Trade Commission for its support while an earlier version of this work was completed and the Center for the Study of Industrial Organization at Northwestern where the most recent draft was completed. 
discriminatory auction to a uniform-price format to issue new securities. Uniform-price auctions are also used for online initial public offerings ("OpenIPOs", including that of Google in August 2004), electricity markets, and markets for emission permits. In such auctions, a bid is a demand schedule, the winners are those who make the highest bids, and all winners pay the same price. In this sense, uniform-price auctions appear analogous to Walrasian markets. One difference, of course, is that bidders are strategic when submitting their demand schedules. In fact, uniform-price auctions often have multiple equilibria with prices as low as the Cournot price (what the literature refers to as "underpricing"). The possibility of underpricing was first observed in Wilson (1979), demonstrated in experimental settings by Goswami, Noe, and Rebello (1996), and shown to be robust to different model specifications by Ausubel and Cramton (1998), Back and Zender (1993), Biais and Faugeron-Crouzet (2002), Engelbrecht and Kahn (1998), Noussair (1994), and Wang and Zender (2002), among others. Despite the warnings of the underpricing literature, uniform-price auctions appear firmly rooted in practice. Thus it becomes important to understand whether it is the uniform-price feature itself that creates opportunities for underpricing and to identify ways to modify the rules of the uniform-price auction so as to eliminate / minimize the extent of underpricing.

This paper adds to the varied literature that analyzes the performance of variations on the standard uniform-price auction. Some recent contributions in this literature include Back and Zender (2001), Kremer and Nyborg (2004a, 2004b), LiCalzi and Pavan (2005), and McAdams (2002). (See Section 5 for a more detailed discussion of these papers.) The new idea here is to allow the seller in the uniform-price auction to be strategic in the sense of being able to decide how much to sell after receiving the bids $\bigsqcup^{1}$ Under such

\footnotetext{
${ }^{1}$ The first paper to introduce the idea of adjustable supply was Lengwiler (1999), but his analysis was restricted to the case in which bids are restricted to two prices. To the best of my knowledge, the
} 
a "adjustable supply rule", the seller in effect commits to maximize its ex post profit given the bids, i.e. to act like a monopolist with respect to announced bidder demand. Of course, in equilibrium bidders will anticipate this adjustable supply and change their bidding behavior accordingly. Perhaps surprisingly, in equilibrium bidders bid so as to counterbalance the seller's monopoly power and the outcome is quite competitive.

Indeed, in a benchmark complete information model having flat demand, all Nash equilibria given adjustable supply implement an efficient outcome at the Walrasian price $p^{W}$. In a richer model having downward sloping demand, there is a unique Nash equilibrium price on order $\frac{1}{N^{3}}$ less than $p^{W}$. By contrast, in the standard uniform-price auction, it is well-known that equilibrium prices never exceed $p^{W}$ and can be as low as the Cournot price, on order $\frac{1}{N}$ less than $p^{W}$.

Is adjustable supply a practical option for some sellers? Yes, indeed some real-world sellers have already adopted variations on adjustable supply. Treasury auctions in Mexico (Umlauf (1993)) and Norway (Bjonnes (2001) and Keloharju, Nyborg, and Rydqvist (2004)) allow the Treasury to reduce the quantity of issued bonds at its discretion after the bids have been received. Since 2002 electricity procurement auctions for basic generation services in New Jersey also have allowed for "decreasable supply". As Salant and Loxley (2002) describe it, "to provide bidders [with] stronger incentives to bid aggressively, the auction rules contained provisions for reducing auction volume if relatively few bidders participated". IPOs in the United States incorporate "increasable supply": the earliest version of this paper ("Adjustable Supply and 'Collusive-Seeming Equilibria' in the UniformPrice Auction", August 1999) was the first to analyze adjustable supply in a broader setting allowing for any price. Two more recent contributions are Bourjade (2004) and Damianov (2004). Bourjade (2004) allows the seller to reduce all bidders' quantities by a percentage of its choosing after receiving the bids. Damianov (2004) considers uniform-price auctions with adjustable supply in which bidders are restricted to bids corresponding to a single price-quantity pair. 
Greenshoe Option allows issuing firms to increase the amount of shares being offered by up to $15 \%$ after receiving bids.

There are several sorts of reasons, however, why adjustable supply may not be a practical option for some sellers. Some sellers may not have the flexibility to adjust supply after receiving the bids. For example, in a spot procurement auction for electricity, the total quantity supplied must match the total quantity being demanded at that instant. Even if there is some flexibility in the quantity demanded, adjustable demand still might not be politically feasible in such applications. Yet another reason is that the seller may not expect bidders to play equilibrium strategies were she to adopt adjustable supply. For example, bidders enjoying low prices in underpricing equilibria of the standard uniformprice auction might threaten not to participate if the seller were to switch to adjustable supply $\left.\right|^{2}$ Or some bidders may find the idea of adjustable supply confusing and bid very tentatively.

The rest of the paper is organized as follows. Section 2 describes the model. Sections 3 and 4 provide the analysis when bidders have flat demand and downward-sloping demand, respectively. Section 5 discusses how the present paper compares and contrasts with the related literature on modifying the uniform-price auction and provides some concluding remarks.

\footnotetext{
${ }^{2}$ A popular explanation for the failure of Google's IPO is very similar. Google's founders stated that their goal was to set a "fair" price as would be predicted in equilibrium. Yet some institutional investors expressed an unwillingness to take part in Google's "social experiment" and, in the end, Google's price still popped from its offering price of $\$ 85$ to $\$ 100$ at the opening bell. As a result, "For major investment banks that reap rich benefits from traditional underwriting practices, the lesson of Google's struggle may be that their franchise is safe" and as one analyst put it, "If I were a CEO going public, I would want to use the traditional approach." (Petruno and Pham (2004)).
} 


\section{$2 \quad$ Model}

I adopt the standard model of the literature on underpricing equilibria in uniform-price auctions, with details patterned after LiCalzi and Pavan (2005). A single (female) seller auctions a homogenous and perfectly divisible good to $n$ (male) bidders using a uniformprice format. The seller need not commit to sell a fixed quantity as in Wilson () and Back and Zender () nor indeed to a supply curve as in LiCalzi and Pavan (). Rather, the seller may commit to any supply rule that maps observed bids into a total quantity to be sold.

Uniform-price auction with a supply rule. Each bidder $i$ simultaneously submits a nonincreasing and left-continuous demand schedule (or "bid") $d_{i}(\cdot)$ specifying his total demand $d_{i}(p)$ at each price $p \geq 0$. Aggregate demand schedule $D(p)=\sum_{i=1}^{n} d_{i}(p)$. The seller's supply rule $S(\cdot)$ specifies the total quantity $S\left(d_{1}(\cdot), \ldots, d_{n}(\cdot)\right)$ to be sold as a function of the bids. For notational simplicity, I shall focus on a subclass of supply rules in which the seller only cares about aggregate demand: $S\left(d_{1}(\cdot), \ldots, d_{n}(\cdot)\right)=$ $S\left(\tilde{d}_{1}(\cdot), \ldots, \tilde{d}_{n}(\cdot)\right) \equiv S(D(\cdot))$ whenever $\sum_{i=1}^{n} d_{i}(p)=\sum_{i=1}^{n} \tilde{d}_{i}(p)=D(p)$ for all $p \geq 0$.

The novel feature of this setup is that the total quantity sold is determined after the bids. Once total quantity $S(D(\cdot))$ is chosen, however, the allocation among the buyers and the price paid is determined in the standard fashion. Define the stop-out price

$$
P=\sup \{p \geq 0 \mid D(p) \geq S(D(\cdot))\}
$$

when the set $\{p \geq 0 \mid D(p) \geq S(D(\cdot))\}$ is non-empty; otherwise let $P=0$. $E(P) \equiv$ $D(P)-S(D(\cdot)) \geq 0$ is the excess demand. When $E(P)=0$, each bidder is allocated quantity $\widehat{d}_{i}(P)=d_{i}(P)$. Otherwise excess demand is rationed pro rata at the margin. 
Let $\triangle d_{i}(P) \equiv d_{i}(P)-\lim _{p \downarrow P} d_{i}(p)$ and $\triangle D(P) \equiv \sum_{i=1}^{n} \triangle d_{i}(P)$. Then bidder $i$ receives

$$
\widehat{d}_{i}(P)=d_{i}(P)-\frac{\triangle d_{i}(P)}{\triangle D(P)} E(P)
$$

Buyers' values

The model is patterned after LiCalzi and Pavan (2005)

A state of the world $\theta=(a, b)$ is observed by the (male) bidders but not by the (female) seller. The seller only knows the distribution of $\theta$. In state $\theta$, each bidder has marginal value schedule $M V\left(q_{i}\right)=a-b q_{i}$ where $a>0$ and $b \geq 0$. The cases when $b=0$ and $b>0$ are called, respectively, "flat demand" and "downward-sloping demand". The seller has zero fixed costs and marginal cost schedule $M C(Q)=c+d Q$ which is common knowledge among all players. The seller's total cost is thus $C(Q)=c Q+d Q^{2} / 2$ and "true supply curve" is $S^{\text {true }}(p)=\frac{p-c}{d}$.

Bids and strategies: A bid in is an inverse demand schedule $I D_{i}(\cdot)$ that specifies a maximal price $I D_{i}\left(q_{i}\right)$ that bidder $i$ is willing to pay for a $q_{i}$-th unit. Any such inverse demand is equivalent to a demand schedule $D_{i}(p) \equiv \max \left\{q_{i}: I D_{i}\left(q_{i}\right) \geq p\right\}$. For any set of bidders $I \subset\{1, \ldots, N\}$, define their aggregate demand $D_{I}(p)=\sum_{i \in I} D_{i}(p)$ and inverse aggregate demand $I D_{I}(Q) \equiv \max \left\{p: D_{I}(p) \geq Q\right\}$. A strategy $I D_{i}(\cdot, \cdot)$ specifies a bid $I D_{i}(\cdot ; \theta)$ for each state of the world.

Supply rule: A supply rule is a mapping from the observed bids into a total quantity to be supplied. I will consider two sorts of supply rules.

Supply curve $S(\cdot)$ rule: When the seller has committed to a supply curve $S(\cdot)$, total quantity is determined by where inverse aggregate demand crosses supply:

$$
Q_{S(\cdot)}(\mathbf{I D}(\cdot)) \equiv \max \left\{Q: I D_{1, \ldots, N}(S(Q)) \geq Q\right\}
$$

In the analysis of Section 3 and Section 4 I will restrict attention to the case in which 
the seller commits to its true supply, $S^{\text {true }}(\cdot)=S(\cdot)$. This restriction will be relaxed in Section 3.3 , however, when I compare my results with those of LiCalzi and Pavan (2005) who allow the seller to strategically commit to supply curves other than true supply.

Responsive supply rule: When the seller has committed to adjustable supply, total quantity is what maximizes its ex post profits:

$$
S_{r e s p}(\mathbf{I D}(\cdot)) \equiv \arg \max _{Q}\left(Q I D_{1, \ldots, N}(Q)-C(Q)\right)
$$

Allocation and price: Once total quantity $Q$ is determined by the supply rule, the uniformprice rules determine how that quantity is allocated and at what price. First, quantity is always allocated to high bidders, meaning that each bidder $i$ always wins at least quantity $\underline{q}_{i}(Q) \equiv \max \left\{q_{i}: I D_{i}\left(q_{i}\right)>I D_{1, \ldots, N}(Q)\right\}$. By construction, $\sum_{i=1}^{N} \underline{q}_{i}(Q) \leq Q$ and $\sum_{i=1}^{N} \bar{q}_{i}(Q) \geq Q$ where $\bar{q}_{i}(Q) \equiv \min \left\{q_{i}: I D_{i}\left(q_{i}\right)<I D_{1, \ldots, N}(Q)\right\}$. Rationing is necessary whenever $\sum_{i=1}^{N} \underline{q}_{i}(Q)<Q$. In this case, I will assume that the seller uses the standard marginal pro rata rationing rule, so that

$$
q_{i}(Q) \equiv \underline{q}_{i}(Q)+\frac{\bar{q}_{i}(Q)-\underline{q}_{i}(Q)}{\sum_{j=1}^{N}\left(\bar{q}_{j}(Q)-\underline{q}_{j}(Q)\right)}
$$

All bidders pay the same price $p(Q)=I D_{1, \ldots, N}(Q)$.

Solution concept: I focus on equilibria in weakly undominated pure strategies. The restriction to pure strategies is mainly for practical reasons: it remains unknown whether or not there can be mixed strategy equilibria in the uniform price auction given any supply rule considered here.

Discussion: (1) Complete information. The presence of underpricing equilibria is most surprising in contexts in which bidders do not have private information. Also, incomplete information settings add technical difficulties that can make the analysis more compli- 
cated without adding much insight. For these reasons, the existing literature on underpricing has focused almost exclusively on this special case and I will do the same. (2) Smoothness assumptions. What is important to the analysis is that marginal values and marginal costs are continuous. None of the results depend on their being differentiable or linear. When the seller has discontinuous marginal costs, however, the adjustable supply rule can become essentially like the decreasable supply rule studied by Back and Zender (2001), so that we lose the ability to eliminate all underpricing equilibria. (See Section 5.)

Simplifications without loss of generality: There are four variables in my model, the price-intercept and slope of bidders' marginal value curve $(a, b)$ and the price-intercept and slope of the seller's marginal cost curve $(c, d)$. For the purpose of characterizing all equilibrium outcomes, however, it suffices to consider the special case that $a=1, c=0$, and $d=1$. To see why, consider first shifting down marginal values and marginal costs by $c$, corresponding to parameter transformation $\mathbf{z}=(a, b, c, d) \rightarrow \mathbf{z}^{\prime}=(a-c, b, 0, d)$. Price $p$ and quantities $\left(q_{1}, \ldots, q_{N}\right)$ is an equilibrium outcome given $\mathbf{z}$ iff price $p-c$ and quantities $\left(q_{1}, \ldots, q_{N}\right)$ is an equilibrium outcome given $\mathbf{z}^{\prime}$. So, without loss set $c=0$. Second, shift down marginal values by $a-1$. Price $p$ and quantities $\left(q_{1}, \ldots, q_{N}\right)$ is an equilibrium outcome given parameters $\mathbf{z}=(a, b, 0, d)$ iff price $p / a$ and quantities $\left(q_{1} / a, \ldots, q_{N} / a\right)$ is an equilibrium outcome given $\left.\mathbf{z}^{\prime}=1, b, 0, d\right)$. So, without loss set $a=1$. Third, flatten both marginal values and marginal costs by a factor of $d$. Price $p$ and quantities $\left(q_{1}, \ldots, q_{N}\right)$ is an equilibrium outcome given parameters $\mathbf{z}=(1, b, 0, d)$ iff price $p$ and quantities $\left(q_{1} / d, \ldots, q_{N} / d\right)$ is an equilibrium outcome given $\mathbf{z}^{\prime}=(1, b / d, 0,1)$. So, without loss set $d=1$. This leaves one free parameter, the steepness $b$ of marginal values. 


\section{$3 \quad$ Flat Demand}

Consider a particular state of the world $\theta=(v, 0)$ in which each bidder $i=1, \ldots, N$ has marginal value $v$ for all units. By the simplification discussed at the end of Section 2 , to characterize all equilibrium outcomes it suffices to consider marginal costs $M C(Q)=Q$ and the case with marginal value $v=1$. For this reason, I will drop the $\theta$ notation in this section.

Walrasian benchmark: In the Walrasian equilibrium, price $p^{W}=1$ and the total quantity supplied is $S^{W}=S^{\text {true }}(1)=1$.

\subsection{True supply}

Suppose first that the seller commits to her true supply curve ("true supply"). Bidding equilibria in this case are well-known. In the equilibrium with the highest price, each bidder bids its true demand, $I D_{i}\left(q_{i}\right)=1$ for all $q_{i}$, and the resulting price $p^{*}=1$ and total quantity $Q^{*}=1$. In the equilibrium with the lowest price, each bidder bids

$$
\begin{aligned}
I D_{i}\left(q_{i}\right) & =1 \text { for all } q_{i}<\frac{1}{N+1} \\
& =\frac{N}{N+1} \text { for all } q_{i} \geq \frac{1}{N+1}
\end{aligned}
$$

(If bidders were able to follow weakly undominated strategies, an easier way to implement this outcome would be for each bidder to announce perfectly inelastic demand à la Cournot.) When bidders $2, \ldots, N$ make this bid, bidder 1 faces residual supply as shown in Figure 1 and prefers price-quantity pair $\left(p^{*}=\frac{N}{N+1}, q_{1}^{*}=\frac{1}{N+1}\right)$. 


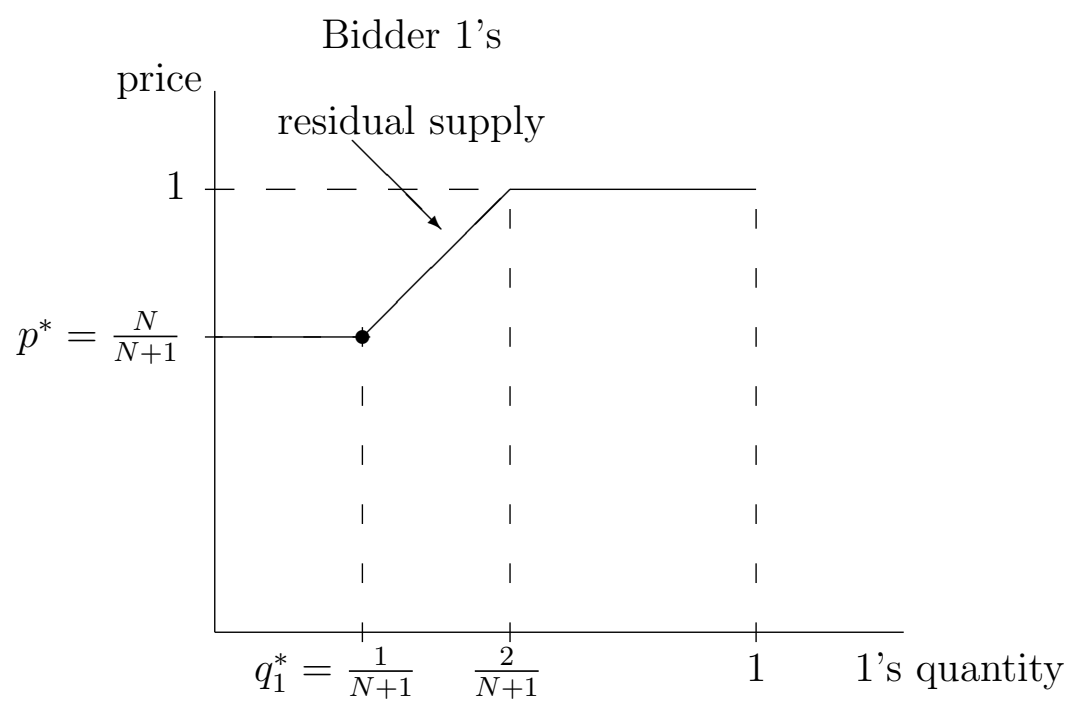

Figure 1: Residual supply in the lowest-price equilibrium given true supply.

\subsection{Responsive supply}

If the seller commits to the adjustable supply rule, all equilibria of the subsequent bidding game lead to a Walrasian outcome.

Theorem 1. In the uniform-price auction with adjustable supply and flat demand, every pure strategy equilibrium in weakly undominated strategies leads to the Walrasian price $p^{r e s p}=1$ and quantity $S^{r e s p}=1$.

Proof. A pure strategy equilibrium in weakly undominated strategies clearly exists: both bidders submit their true demand schedules and the seller chooses to supply $S^{\text {true }}(1)$. (Since announced demand is perfectly elastic, the seller does not choose to withhold any quantity.)

Part I: Price equals 1 in every equilibrium. Clearly price can never exceed 1. Suppose now that there is an equilibrium in which $p^{r e s p}<1$. Several steps will lead to a contradiction. First, the seller must choose not to withhold any quantity, i.e. $S^{\text {resp }}=S^{\text {true }}\left(p^{\text {resp }}\right)$. 


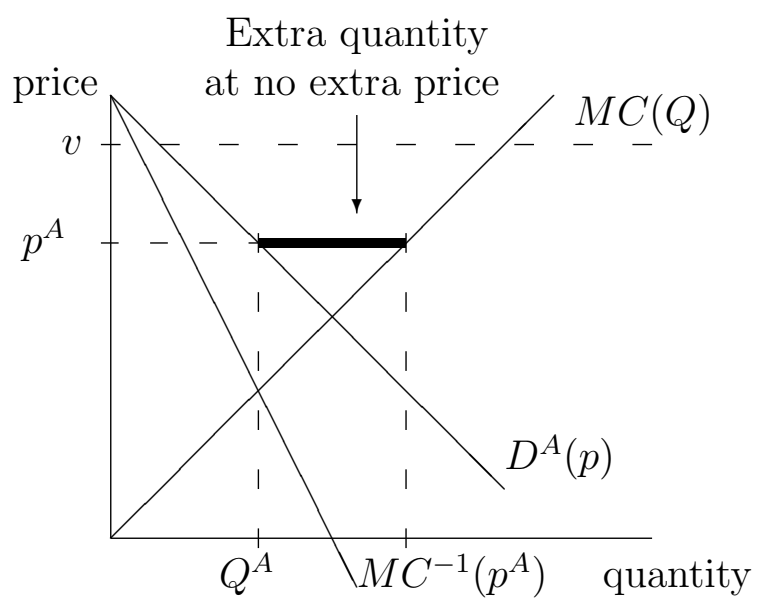

Figure 2: Part I, first step. If $p^{\text {resp }}<1$, then $S^{\text {resp }}=S^{\text {true }}\left(p^{\text {resp }}\right) .\left(M R_{1, \ldots, N}(\cdot)\right.$ denotes the seller's ex post marginal revenue curve.)

Suppose otherwise and that each bidder $i$ gets $q_{i}^{\text {resp }}$ units such that $S^{\text {resp }}=q_{1}^{\text {resp }}+q_{2}^{\text {resp }}<$ $S^{\text {true }}\left(p^{\text {resp }}\right)$. Consider the following deviation $I D_{1}(\cdot)$ for bidder 1 from its equilibrium $\operatorname{bid} I D_{1}^{r e s p}(\cdot)$ :

$$
\begin{aligned}
\tilde{I D}_{1}(q) & =I D_{1}^{\text {resp }}(q) \text { for all } q<q_{1}^{\text {resp }} \\
& =p^{\text {resp }} \text { for all } q \geq q_{1}^{\text {resp }}
\end{aligned}
$$

When bidder 1 deviates in this way, the seller will choose to supply $S^{\text {true }}\left(p^{r e s p}\right)$ at the same price $p^{\text {resp }}$ and bidder 1 will get an additional $S^{\text {true }}\left(p^{\text {resp }}\right)-S^{\text {resp }}$ units. Since $p^{r e s p}<1$, this deviation makes bidder 1 strictly better off.

Second, the seller chooses to withhold no quantity only if announced demand is locally perfectly elastic to the left of $S^{r e s p}$, i.e. $\lim _{\varepsilon \rightarrow 0} I D_{1, \ldots, N}^{\text {resp }}{ }^{\prime}\left(S^{\text {resp }}-\varepsilon\right)=0$. This requires that $\lim _{\varepsilon \rightarrow 0} I D_{i}^{\text {resp }}\left(q_{i}^{\text {resp }}-\varepsilon\right)=0$ for some $i$. Without loss, suppose that this condition holds for some $i \neq 1$. Consider the following deviation $\tilde{I}_{1}^{\varepsilon}(\cdot)$ for bidder 1 from its equilibrium 


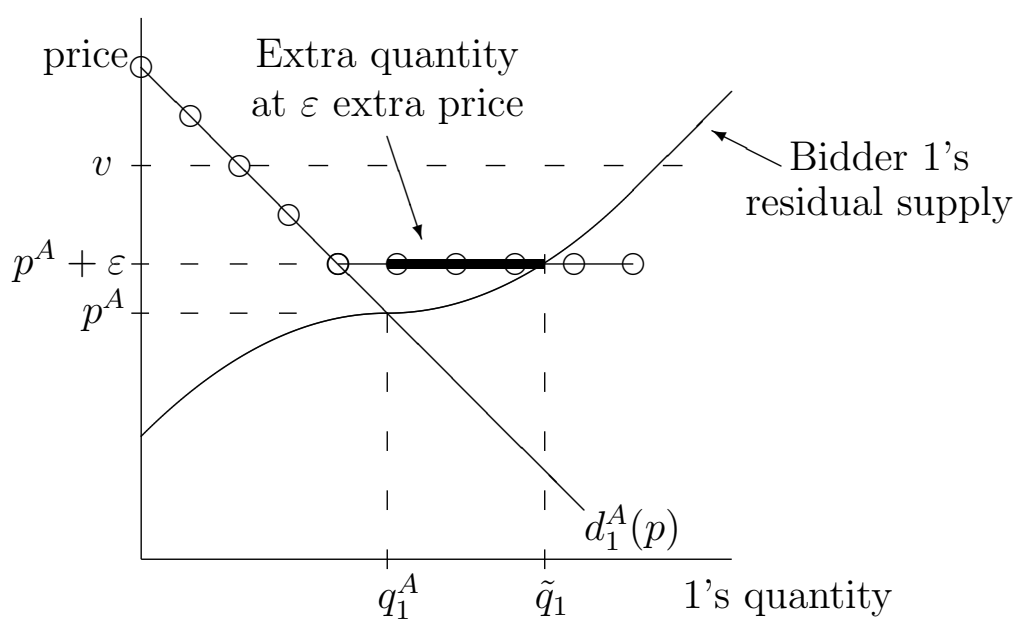

Figure 3: Part I, second step. If residual supply is locally perfectly elastic at $p^{\text {resp }}$, then $p^{r e s p}=1 .\left(R S_{q}(\cdot)\right.$ denotes bidder 1's residual supply curve. $)$

$\operatorname{bid} I D_{1}^{\text {resp }}(\cdot)$ :

$$
\begin{aligned}
\tilde{I D}_{1}^{\varepsilon}(q) & =I D_{1}^{\text {resp }}(q) \text { for all } q \text { such that } I D_{1}^{\text {resp }}(q)>p^{\text {resp }}+\varepsilon \\
& =p^{\text {resp }}+\varepsilon \text { for all other } q \leq 1
\end{aligned}
$$

After this deviation, the seller will again choose not to withhold any quantity, so that $\tilde{S}=S^{\text {true }}\left(p^{\text {resp }}+\varepsilon\right)$ and $\tilde{q}_{1} \geq S^{\text {true }}\left(p^{\text {resp }}+\varepsilon\right)-\sum_{j \neq 1} D_{2, \ldots, N}^{\text {resp }}\left(p^{\text {resp }}+\varepsilon\right)$. Consequently, bidder 1 must get at least

$$
\triangle_{q_{1}}(\varepsilon) \equiv\left(S^{\text {true }}\left(p^{\text {resp }}+\varepsilon\right)-S^{\text {true }}\left(p^{\text {resp }}\right)\right)+\left(q_{2}^{\text {resp }}-\sum_{j \neq 1} D_{2, \ldots, N}^{\text {resp }}\left(p^{\text {resp }}+\varepsilon\right)\right)
$$

additional quantity at price $p^{r e s p}+\varepsilon$ and pay an additional $\varepsilon$ on its equilibrium quantity $q_{1}^{\text {resp }}$. Since $\lim _{\varepsilon \rightarrow 0} I D_{2, \ldots, N}^{\text {resp }}{ }^{\prime}\left(q_{2}^{\text {resp }}-\varepsilon\right)=0$, however, there exists $\varepsilon>0$ such that

$$
\lim _{\varepsilon \rightarrow 0} \frac{\left(1-p^{r e s p}\right) \triangle_{q_{1}}(\varepsilon)}{\varepsilon q_{1}^{r e s p}}=\infty
$$

so that some such deviation is profitable for bidder 1. 


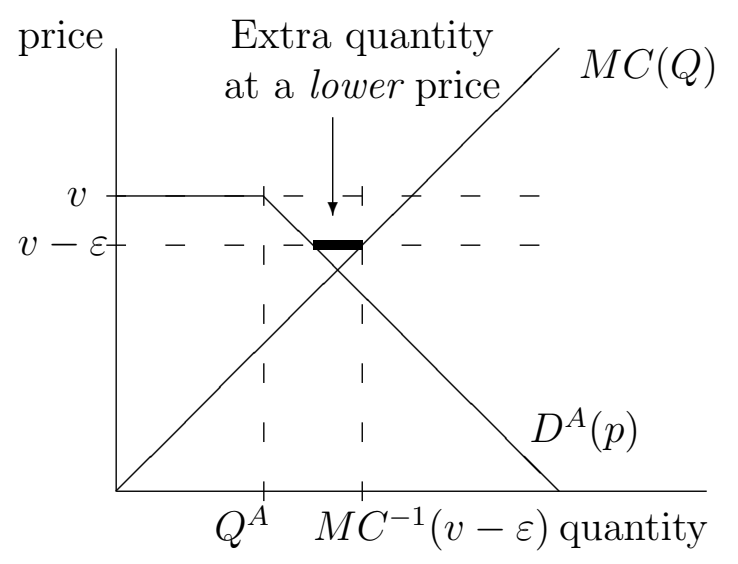

Figure 4: Part II. If $p^{\text {resp }}=1$, then $S^{\text {resp }}=S^{\text {true }}(1)$.

Part II: $S^{\text {resp }}=S^{\text {true }}(1)$. Suppose that $p^{\text {resp }}=1$ and $S^{\text {resp }}<S^{\text {true }}(1)$. Consider the following deviation for bidder 1:

$$
\begin{aligned}
\widehat{I D}_{1}^{\varepsilon}(q) & =I D_{1}^{r e s p}(q) \text { for all } q \text { such that } I D_{1}^{r e s p}(q)>1-\varepsilon \\
& =1-\varepsilon \text { for all other } q \leq 1
\end{aligned}
$$

For small enough $\varepsilon$, the seller's best response is to supply $S^{\text {true }}\left(p^{r e s p}-\varepsilon\right)$ units at price $p^{r e s p}-\varepsilon$ so that bidder 1 gets at least $S^{\text {true }}\left(p^{r e s p}-\varepsilon\right)>I D_{1, \ldots, N}\left(p^{r e s p}-\varepsilon\right)>0$ additional units and pays a lower price than before. Thus, this is a profitable deviation for bidder 1.

\section{3 "Strategic supply" vs. adjustable supply}

LiCalzi and Pavan (2005) study "strategic supply" in which the seller first strategically commits to a linear supply curve and then bidders play the symmetric Nash equilibrium that is best for the bidders (and worst for the seller). They find that the seller gains by 
committing to a supply curve that is more elastic than its true supply because doing so reduces the extent of underpricing. If adjustable supply were also an option available to the seller, however, she would never commit to any supply curve other than true supply.

To see why, consider a simple example with $N$ bidders in which $v$ is random and marginal costs $M C(Q)=Q$. All equilibria given adjustable supply and value $v$ lead to price $p^{W}=v$ and total quantity $Q^{W}=v$ for profit $\frac{v^{2}}{2}$. If the seller commits to some other supply curve with $S(v) \neq S^{\text {true }}(v)$ for some $v$, however, even the best subsequent bidding equilibrium given value $v$ leads an inefficient outcome with seller's profit strictly less than $\frac{v^{2}}{2}$.

It is worth noting that the seller might be indifferent between the adjustable supply and committing to its true supply rule if bidders will always play the most competitive subsequent Nash equilibrium given true supply. To explore this issue further, the next section allows for downward-sloping demand and shows that it is possible that the seller may strictly prefer true supply to adjustable supply.

\section{Downward-Sloping Demand}

Now, it suffices to consider the case when bidders have marginal value curves $M V_{i}\left(q_{i}\right)=$ $1-b q_{i}$ and the seller has marginal cost curve $M C(Q)=Q$. For this reason, I will refer to the state of the world $\theta=(1, b)$ simply as $b$.

Walrasian benchmark: In the Walrasian equilibrium, price $p^{W}(b, N)$ must equate supply $p$ with aggregate demand $\frac{N(1-p)}{b}$. Thus,

$$
p^{W}(b, N)=\frac{N}{b+N}
$$

and the total quantity supplied $S^{W}(b, N)=\frac{N}{b+N}$ for all $b>0$. 
Example: I will return to the following specific example throughout this section: $N=2$ (two bidders) and $b=1\left(M V_{i}\left(q_{i}\right)=1-q_{i}\right)$. In Walrasian equilibrium, $p^{W}(1,2)=\frac{2}{3}$ and $S^{W}(1,2)=\frac{2}{3}$.

\subsection{True supply}

Despite the extensive literature studying underpricing in uniform-price auctions given a fixed supply schedule, the minimal and maximal extent to which equilibrium prices can be below the Walrasian price is not known in the downward-sloping demand case. The most comprehensive existing analysis along these lines that I am aware of is provided by Klemperer and Meyer (1989). Yet Klemperer and Meyer restrict attention to equilibria in twice differentiable bid schedules, and (as we shall see) discontinuous bids can help sustain lower prices. Back and Zender (1993) and LiCalzi and Pavan (2005), among others, have studied underpricing equilibria with discontinuous bid schedules but only for the case of flat demand. Restricting attention to weakly undominated strategies as I do here also introduces new issues not addressed in the previous literature.

Which prices can be supported in equilibrium? Suppose that there is a bidding equilibrium with price $p^{*}$ and allocation $\mathbf{q}^{*}=\left(q_{1}^{*}, q_{2}^{*}\right)$. Since the seller has committed to true supply $S^{\text {true }}(p)=p$ ), one necessary condition is that $p^{*}=q_{1}^{*}+q_{2}^{*}$. More importantly, each bidder $i$ must submit a demand schedule $I D_{i}\left(q_{i} ; b\right)$ such that bidder $j \neq i$ weakly prefers the point $\left(p^{*}, q_{j}^{*}\right)$ over all other points on its residual supply schedule. Next, note that bidder $j$ is more likely to find $\left(p^{*}, q_{j}^{*}\right)$ to be the best point on its residual supply schedule the higher that schedule is at other quantities. Given the restriction to weakly undominated strategies, however, an upper bound on residual supply is created by the fact that bidder $i$ must bid less than or equal to its true marginal value for each unit: $I D_{i}\left(q_{i} ; b\right) \leq 1-b q_{i}$ 
for all $q_{i}$. (Bidding more than marginal value is weakly dominated; bidding less than or equal to marginal value is not.) Thus, to check whether outcome $\left(p^{*}, \mathbf{q}^{*}\right)$ can be supported in equilibrium, it suffices to consider the case in which each bidder $i=1,2$ submits the following bid schedule:

$$
\begin{aligned}
I D_{i}\left(q_{i} ; b\right) & =M V_{i}\left(q_{i} ; b\right)=1-b q_{i} \text { for all } q_{i}<q_{i}^{*} \\
& =p^{*} \text { for all } q_{i} \in\left[q_{i}^{*}, \frac{1-p^{*}}{b}\right] \\
& =1-b q_{i} \text { for all } q_{i}>\frac{1-p^{*}}{b}
\end{aligned}
$$

Return to the example: Recall that there are $N=2$ bidders having marginal values $M V_{i}\left(q_{i}\right)=1-q_{i}$ and that the seller's supply is $S(p)=1-p$. Thus, when bidder 2 bids according to (3), bidder 1 faces residual supply

$$
\begin{aligned}
R S_{1}(p) & =R S_{1}^{\text {true }}(p)=p-(1-p)=2 p-1 \text { for all } p>1-q_{2}^{*} \\
& =p-q_{2}^{*} \text { for all } p \in\left[p^{*}, 1-q_{2}^{*}\right] \\
& =2 p-1 \text { for all } p<p^{*}
\end{aligned}
$$

(Note that there is typically a discontinuity in residual supply at $p^{*}$.)

Figure 5 illustrates bidder 1's residual supply when $p^{*}=\frac{5}{8}$ and $q_{1}^{*}=\frac{3}{8}$ and $q_{2}^{*}=\frac{1}{4}$. To check whether this is incentive compatible for bidder 1, note that bidder 1 may have two sorts of profitable deviations: bidder 1 may prefer to deviate by getting more quantity at a higher price than $p^{*}$ or by getting less quantity at a lower price. In Figure 5 , bidder 1 does not want more quantity for the simple reason that $\frac{3}{8}$ is his Walrasian quantity, i.e. his marginal value is less than $p^{*}$ for additional quantity. What about getting less? If bidder 1 reduces its quantity to $q_{1} \leq \frac{1}{4}$, then price will be $\frac{1}{2}+\frac{q_{1}}{2}$ and its average value will be $1-\frac{q_{1}}{2}$ for overall profit $q_{1}\left(\frac{1}{2}-q_{1}\right)$ so that all quantities less than $\frac{1}{4}$ give less profit 


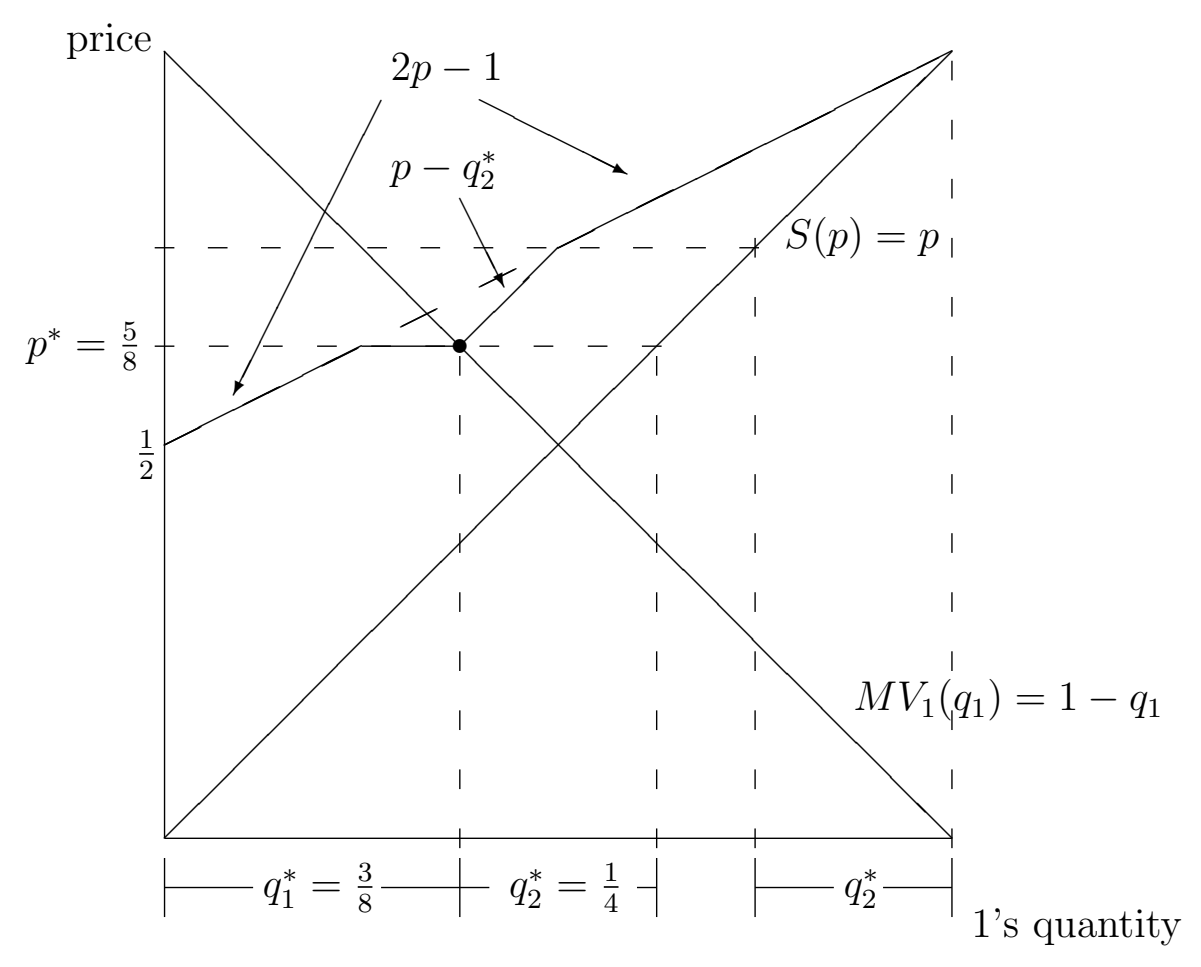

Figure 5: $\left(p^{*}, q_{1}^{*}\right)$ is incentive compatible for bidder $1(N=2$ and $b=1)$.

than $q_{1}=\frac{1}{4}$ at price $\frac{5}{8}$. Of course, bidder 1 is even better off with quantity $q_{1}=\frac{3}{8}$ at price $\frac{5}{8}$. Thus, this price-quantity pair is incentive compatible for bidder 1 .

Similarly (though for a different reason), price $p^{*}=\frac{5}{8}$ and quantity $q_{2}^{*}=\frac{1}{4}$ is incentive compatible for bidder 2 . To see this, note that the fact that bidder 1 pays his marginal value implies that bidder 2's residual supply coincides with its true residual supply. When facing true residaul supply, however, bidder 2 maximizes its profit by setting $q_{2}^{*}=\frac{1}{4}$, exactly what bidder 2 is receiving.

By the same reasoning, the Walrasian outcome $\left(p^{*}=\frac{2}{3}, q_{1}^{*}=\frac{1}{3}, q_{2}^{*}=\frac{1}{3}\right)$ is not incentive compatible. Since $M V_{1}(1 / 3)=2 / 3$, bidder 2's residual supply again corresponds to true residual supply so that his best response is to demand $q_{2}=1 / 4 \neq 1 / 3$. For this reason, price $p=2 / 3$ is not sustainable in equilibrium; every equilibrium involves some 


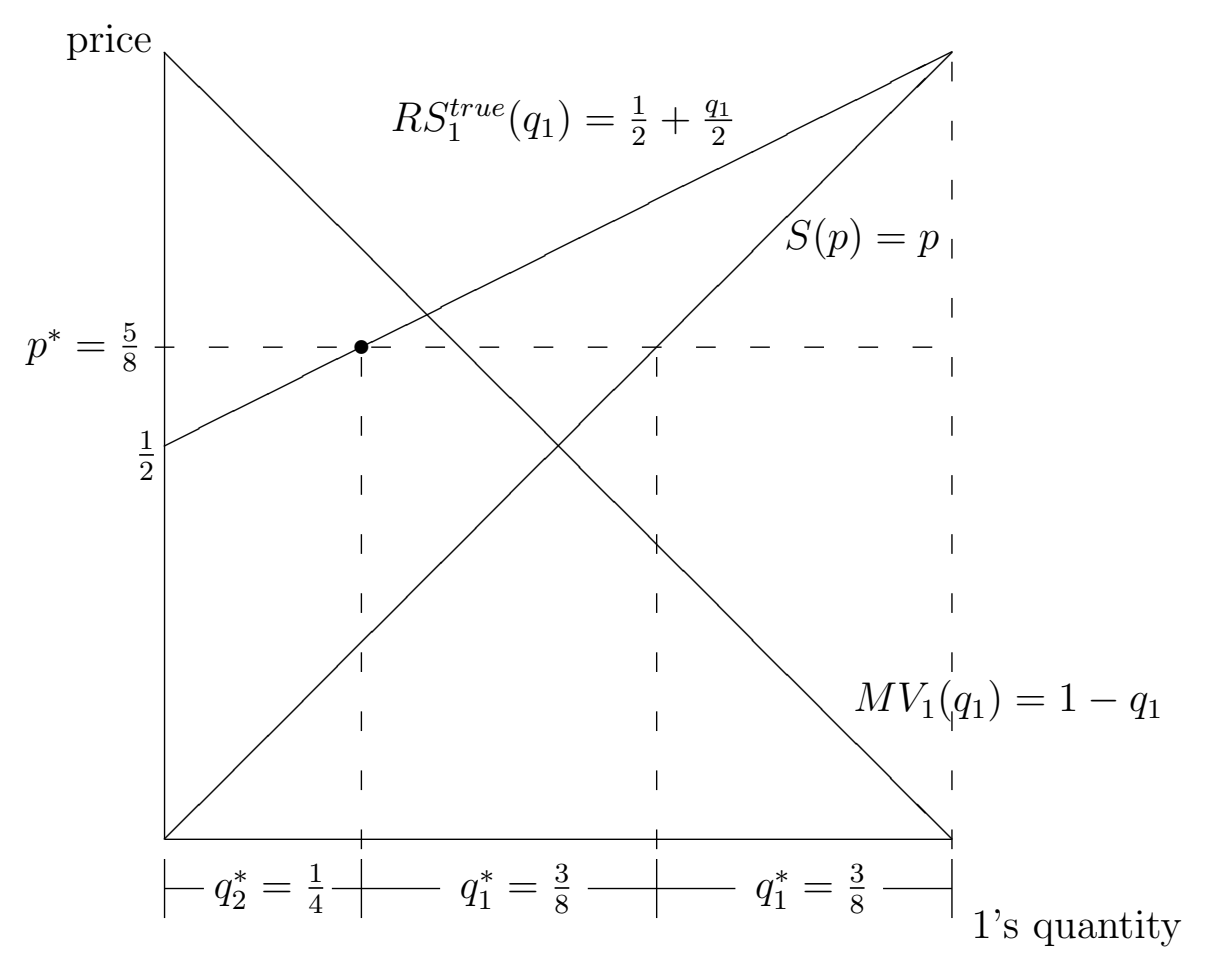

Figure 6: $\left(p^{*}, q_{2}^{*}\right)$ is incentive compatible for bidder $2(N=2$ and $b=1)$.

underpricing.

Proposition 1. When $b=1$ and $N=2$, a bidding equilibrium given true supply exists in which the realized price is $p^{*}$ iff $p^{*} \in\left[\frac{1}{2}, \frac{2}{5}+\frac{\sqrt{6}}{10}\right] \approx[.5, .645]$

Proof. Suppose first that $p^{*}<\frac{1}{2}$. Without loss, we may further suppose that $q_{1}^{*}<\frac{1}{4}$. Bidder 1 then has an incentive to slightly increase the quantity that it receives. To see this, note that his marginal value is $1-q_{1}^{*}>\frac{3}{4}$ while his marginal expenditure is $p^{*}+q_{1}^{*}<\frac{3}{4}$.

Since we are simply interested in what prices can be sustained in equilibrium, it suffices consider symmetric allocations: if both bidders prefer not to deviate given price $p^{*}$ and quantities $\left(q_{1}^{*}, q_{2}^{*}\right)$, then they will also prefer not to deviate given price $p^{*}$ and 
quantities $(\tilde{q}, \tilde{q})$ where $\tilde{q}=\frac{q_{1}^{*}+q_{2}^{*}}{2}$. Now, there are four potential sorts of deviations corresponding to the four pieces of bidders' residual supply curves: (i) Reduce quantity a lot, corresponding to the lower part of true residual supply. (ii) Reduce quantity a little, corresponding to the flat part of residual supply. (iii) Increase quantity a little, corresponding to the part of residual supply with slope 1. (iv) Increase quantity a lot, corresponding to the upper part of true residual supply.

The argument of the first paragraph shows that as long as $p^{*} \geq \frac{1}{2}$, then no type(iii) deviation is profitable. Furthermore, obviously no type-(ii) deviation is profitable. What about the others? If it were facing the entire true residual supply, each bidder maximizes profit at quantity $\frac{1}{4}$ and price $\frac{5}{8}$ for profit of $\frac{1}{16}$. (The bidder's average value is $\left.\frac{7}{8}\right)$. Furthermore, when a bidder chooses not to deviate from price-quantity pair $\left(p^{*}, \frac{p^{*}}{2}\right)$, he has average value $1-\frac{p^{*}}{4}$ and so gets profit $\frac{p^{*}}{2}\left(1-\frac{p^{*}}{4}-p^{*}\right)$. This is greater than $\frac{1}{16}$ as long as $p^{*} \in\left[\frac{2}{5}-\frac{\sqrt{6}}{10}, \frac{2}{5}+\frac{\sqrt{6}}{10}\right] \approx[.155, .645]$. Consequently, there is a symmetric equilibrium that supports all prices $p^{*} \in[.5, .645]$.

Finally, it is obvious that no price higher than the Walrasian price $\left(\frac{2}{3} \approx .667\right)$ can be achieved in equilibrium. So suppose that $p^{*} \in[.645, .667]$. Since $q^{*}>\frac{1}{4}$, each bidder has access to a deviation that gives profit $\frac{1}{16}$. Consequently, one can not support any price in this range.

The two main features of Proposition 1 carry over to the general case with $N$ bidders and any downward sloping demand: (i) the lowest price that can be sustained in a bidding equilibrium is the Cournot price and (ii) the highest price that can be sustained is strictly less than the Walrasian price.

Theorem 2 (Range of equilibrium prices under true supply). The prices that can be sustained in a bidding equilibrium (in weakly undominated strategies) when the seller has 
committed to true supply are $[\underline{p}(b, N), \bar{p}(b, N)]$, where

$$
\underline{p}(b, N)=\frac{N}{b+N+1}
$$

is the Cournot price and $\bar{p}(b, N)<p^{W}(b, N)$ the Walrasian price.

Proof. The Walrasian price can not be sustained in equilibrium. If so, each bidder would pay his marginal value but be able to reduce the price by slightly reducing his quantity. (Here I use the restriction that other bidders adopt weakly undominated strategies, i.e. they do not bid more than their willingness to pay for units that they do not win.)

Now, suppose that price $p^{*}<\frac{N}{b+N+1}$ could be sustained in equilibrium. Then some bidder $i$ would have to get quantity $q_{i}^{*}<\frac{1}{b+N+1}$. Since all other bidders' announced demand schedules are inelastic for slightly more quantity (see equation (3) and the justification thereof), bidder $i$ 's residual supply has the same slope as the seller's supply curve, i.e. increasing his quantity by one unit raises price by one unit. Consequently, bidder $i$ 's marginal value from an additional unit is $1-b q_{1}^{*}>\frac{N+1}{b+N+1}$ while his marginal expenditure is $p^{*}+q_{i}^{*}<\frac{N+1}{b+N+1}$, a contradiction.

On the other hand, mirroring the argument in the proof of Proposition 1, when bidders make symmetric bids according to equation (3) for any price $p^{*} \geq \frac{N}{b+N+1}$, they will not have the incentive to acquire slightly more quantity.

Finally, when prices are above the adjustable supply price $p^{\text {resp }}$ and close enough to the Walrasian price $p^{W}$, bidders will benefit from deviating by taking less quantity. The exact price at which this happens can be determined in much the same way as the threshold $\frac{2}{5}+\frac{\sqrt{6}}{10}$ was found in the proof of Proposition 1 . 


\subsection{Responsive supply}

Given adjustable supply there is a unique equilibrium price and, up to permutation of the bidders, a unique equilibrium allocation.

Theorem 3. Every pure strategy equilibrium in weakly undominated strategies leads to the same price when the seller has committed to adjustable supply. As a function of the number of bidders $N$ and marginal value slope $b$, this price is

$$
p^{r e s p}(b, N)=\frac{N(b+N)-1}{(b+N)^{2}-1}
$$

Furthermore, all equilibria are asymmetric and support a unique equilibrium allocation up to permutation of the bidders:

$$
q_{1}^{\text {resp }}(b, N)=\frac{1}{b+(N+1)} \text { and } q_{i}^{\text {resp }}(b, N)=\frac{b+N}{(b+N)^{2}-1} \text { for all } i \neq 1
$$

Proof. The proof proceeds in several steps. Several of these steps are closely linked to earlier analysis, as indicated in brackets.

Step 1: Some bidder pays less than marginal value, i.e. $M V_{1}\left(q_{1}^{\text {resp }}\right)>p^{\text {resp }}$. Suppose instead that $M V_{i}\left(q_{i}^{\text {resp }}\right)=p^{\text {resp }}$ for all $i$. Since each bidder $i$ has decreasing marginal values and is restricted to play weakly undominated strategies, bidder 1's residual supply must be downward sloping to the left of his equilibrium allocation. Since bidder 1's marginal value equals price, however, he must prefer to slightly decrease his quantity since this will lower the price. Without loss, then, suppose that $M V_{1}\left(q_{1}^{\text {resp }}\right)>p^{\text {resp }}$.

Step 2: The seller does not withhold any quantity, i.e. $\sum_{i=1}^{N} q_{i}^{\text {resp }}=S^{\text {true }}\left(p^{\text {resp }}\right)$. [Almost the same as the first step of Part I in the proof of Proposition 1. See Figure 2.] Suppose that $\sum_{i=1}^{N} q_{i}^{\text {resp }}<S^{\text {true }}\left(p^{\text {resp }}\right)$. This is only possible if aggregate announced demand is downward-sloping at the equilibrium price-total quantity. But in this case bidder 1 
can deviate so as to get strictly more quantity without increasing the price. (The only difference with the argument in the proof of Proposition 1 is that bidder 1 may choose to deviate so as to win some but not all of the extra quantity.) This makes bidder 1 strictly better off since $M V_{1}\left(q_{1}^{r e s p}\right)>p^{r e s p}$.

Comment regarding "residual supply". Since the seller has adjustable supply, strictly speaking bidders do not have residual supply curves as in the case of true supply. Because of Step 2, however, we know that in equilibrium the seller will not withhold any quantity so that each bidder $i$ will receive a quantity on what his residual supply would be if the seller had committed to true supply. Furthermore, if a bidder has a profitable deviation, then its best deviation will lead the seller not to withhold any quantity. In essence, then, each bidder selects a price-quantity pair on its residual supply curve just as in the case of true supply. For the rest of the proof, then, I will refer to each bidder's "residual supply" in this sense.

Step 3: Every bidder $i \neq 1$ pays his marginal value, i.e. $M V_{i}\left(q_{i}^{\text {resp }}\right)=p^{\text {resp }}$ for all $i \neq 1$. [Almost the same as the second step of Part I in the proof of Proposition 1. See Figure 3.] Since by Step 2 the seller chooses not to withhold any quantity, some bidder (say bidder $j$ ) must submit an inverse demand schedule that is locally flat to the left of $q_{j}^{\text {resp }}$, implying that each bidder $i \neq j$ 's residual supply is locally flat to the right of $q_{i}^{\text {resp }}$. Yet this means that bidder $i$ can get significantly more quantity while only slightly raising the price. (See equation (1).) This is not a profitable deviation for bidder $i$ only if $M V_{i}\left(q_{i}^{r e s p}\right)=p^{r e s p}$. Consequently, it must be that $j=1$ and that $M V_{i}\left(q_{i}^{\text {resp }}\right)=p^{r e s p}$ for all $i \neq 1$.

Summarizing Steps 1-3. Without loss we may assume that $M V_{1}\left(q_{1}^{\text {resp }}\right)>p^{\text {resp }}, M V_{i}\left(q_{i}^{\text {resp }}\right)=$ $p^{\text {resp }}$ for all $i \neq 1$, and $\sum_{i=1}^{N} q_{i}^{\text {resp }}=S^{\text {true }}\left(p^{\text {resp }}\right)$. 
Step 4: Bidder 1 must be rationed, i.e. $D_{1}^{-}\left(p^{\text {resp }}\right)<q_{1}^{\text {resp }}<D_{1}^{+}\left(p^{\text {resp }}\right)$. If bidder 1 is not rationed, any other bidder $i \neq 1$ can decrease the price by slightly reducing his quantity. This would be a profitable deviation since $M V_{i}\left(q_{i}^{\text {resp }}\right)=p^{\text {resp }}$. On the other hand, when bidder 1 is rationed, each other bidder must sacrifice a chunk of quantity before price is affected at all.

Step 5: Without loss, every bidder $i \neq 1$ bids his true demand, i.e. $D_{i}(p)=I M V_{i}(p)$ for all $p$. (Recall that $I M V$ denotes inverse marginal values.) First, $D_{i}(p) \leq I M V_{i}(p)$ for all $p$ since otherwise bidder $i$ 's strategy would be weakly dominated. Second, $D_{i}\left(p^{\text {resp }}\right)=$ $I M V_{i}\left(p^{\text {resp }}\right)$ since bidder $i$ pays his marginal value. Third, by the logic surrounding equation (3), bidders $j \neq i$ are most deterred from deviating from their equilibrium strategies when bidder $i$ bids for as much quantity as possible consistent with the previous two points, i.e. $D_{i}(p)=I M V_{i}(p)$ for all $p$. Without loss, then, we may assume that every bidder $i \neq 1$ bids his true demand.

Step 6: There is a unique equilibrium price and, up to permutation of the bidders, a unique equilibrium allocation. [See discussion surrounding Figure 6.] Step 5 specifies the equilibrium strategy of every bidder $i \neq 1$. This is enough to know that bidder 1's residual supply curve looks like Figure 6:

$$
\begin{aligned}
R S_{1}(p) & =S^{\text {true }}(p)-(N-1) \operatorname{IMV}(p)=p-(N-1) \frac{1-p}{b} \\
& =\frac{b+N-1}{b}\left(p-\frac{N-1}{b+N-1}\right)
\end{aligned}
$$

with inverse residual supply

$$
\operatorname{IRS} S_{1}\left(q_{1}\right)=\frac{b}{b+N-1}\left(q_{1}+\frac{N-1}{b}\right)
$$

Since inverse residual supply has no kinks or discontinuities, bidder 1 must be indifferent to slightly raising or lowering its quantity from $q_{1}^{\text {resp }}$. Bidder 1's marginal value is 
$M V_{1}\left(q_{1}^{r e s p}\right)=1-b q_{1}^{r e s p}$ and his marginal expenditure is

$$
\begin{aligned}
M E_{1}\left(q_{1}^{r e s p}\right) & =I R S_{1}\left(q_{1}^{r e s p}\right)+q_{1}^{r e s p} \frac{\mathrm{d} I R S_{1}}{\mathrm{~d} q_{1}}\left(q_{1}^{r e s p}\right) \\
& =\frac{2 b}{b+N-1} q_{1}^{r e s p}+\frac{N-1}{b+N-1}
\end{aligned}
$$

Solving $M V_{1}\left(q_{1}^{\text {resp }}\right)=M E_{1}\left(q_{1}^{\text {resp }}\right)$ then yields

$$
q_{1}^{r e s p}=\frac{1}{b+N+1}
$$

Since $q_{i}^{\text {resp }}=1-b p^{\text {resp }}$ for all $i \neq i$ by Step 5 and $\sum_{i=1}^{N} q_{i}^{\text {resp }}=p^{\text {resp }}$ by Step 2, we get

$$
q_{i}^{\text {resp }}=\frac{b+N}{(b+N)^{2}-1} \text { for all } i \neq 1 \text { and } p^{r e s p}=\frac{N(b+N)-1}{(b+N)^{2}-1}
$$

Step 7: Bidders $i \neq 1$ prefer not to deviate. [See discussion surrounding Figure 5.] So far we have shown that there is a unique price and allocation consistent with the requirements of equilibrium, in particular that bidder 1 not prefer to deviate. It remains to check, however, whether other bidders (say bidder 2) may prefer to deviate. For this purpose, suppose that bidder 1 makes the following bid in equilibrium:

$$
I D_{1}\left(q_{1} ; b\right)=p^{r e s p} \text { for all } q_{1}<q_{1}^{\text {resp }} \quad=M V_{i}\left(q_{i} ; b\right)=1-b q_{i} \text { for all } q_{i} \geq q_{i}^{\text {resp }}
$$

(Bidder 1 can not submit inverse demand having a discontinuity as in the case of true supply since the seller will then choose to withhold some quantity.) Then bidder 2 faces residual supply as traced by $\times$ 's in Figure 7. Clearly, bidder 2 does not want to get more quantity than $q_{2}^{r e s p}$ since $M V_{2}\left(q_{2}^{r e s p}\right)=p^{\text {resp }}$. On the other hand, by our previous analysis of bidder 1, the best point on bidder 2's residual supply over the range of lower quantities is $\tilde{q}=q_{1}^{\text {resp }}$ at price $p^{\text {resp }}$. (Bidder 1's residual supply coincides with that of bidder 2 for quantities up to $q_{1}^{\text {resp }}$.) Clearly, bidder 2 is better off getting $q_{2}^{\text {resp }}>q_{1}^{\text {resp }}$ at that price. 


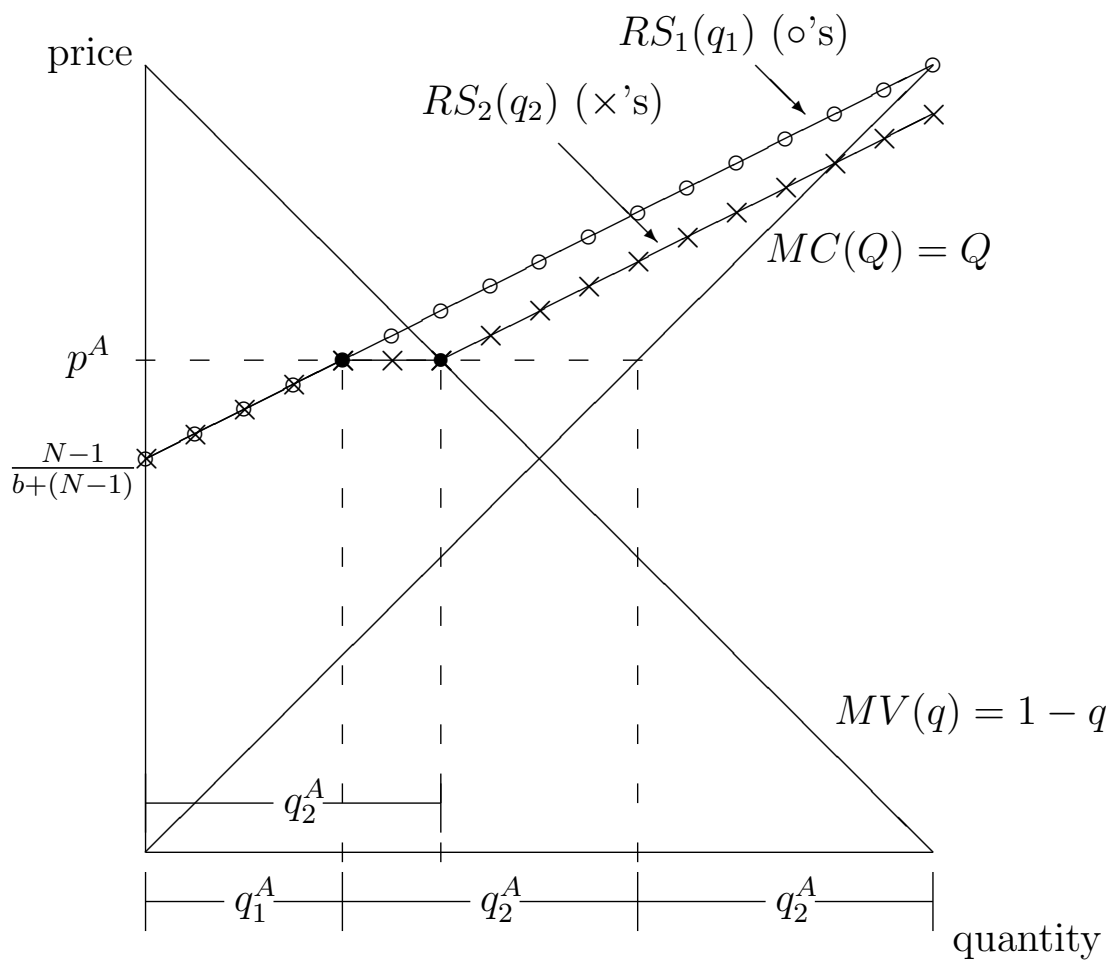

Figure 7: "Residual supply curves" of bidder 1 and of all other bidders (say bidder 2) in equilibrium given adjustable supply.

This completes the proof: $\left(p^{r e s p}, \mathbf{q}^{\text {resp }}\right)$ as specified in equations (6] 7 is an equilibrium outcome. Furthermore, all equilibria lead to the same price and allocation up to permutation of the bidders.

Return to the example $(N=2, b=1)$. When $N=2$ and $b=1, q_{1}^{\text {resp }}=\frac{1}{4}, q_{2}^{\text {resp }}=\frac{3}{8}$, and $p^{\text {resp }}=\frac{5}{8}$. Bidder 1's residual supply is precisely that in Figure 6. Bidder 2's residual supply is a special case of that in Figure 7 .

Example continued $(N=2, b=1)$. If the seller commits to true supply, subsequent bidding equilibria may lead to any price in $[.5, .645]$. If she commits to adjustable supply, however, she can guarantee price .625 in any subsequent bidding equilibrium. Clearly, 


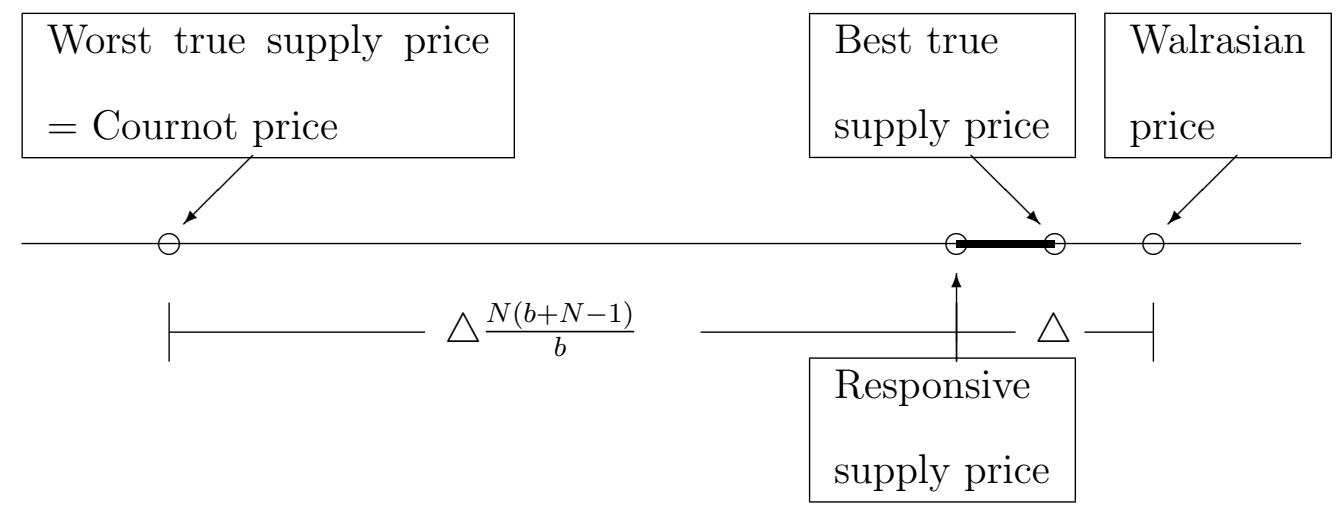

Figure 8: Shaded line segment contains prices that can be achieved given true supply but not adjustable supply. $\triangle$ is on order $\frac{1}{N^{3}}$.

then, there are two sorts of subgame perfect equilibria: (i) the seller commits to true supply and the price is relatively high $(p \in[.625, .645])$; (ii) the seller commits to adjustable supply and, if it had committed to true supply, the price would have been relatively low $(p \in[.5, .625])$.

\subsection{True supply vs. adjustable supply}

The previous analysis shows that, given downward-sloping demand, we can not unambiguously rank true supply and adjustable supply. Which raises more revenue will depend on which bidding equilibrium bidders play given true supply. If bidders always play the highest-price (or lowest-price) equilibrium given true supply, then adjustable supply raises less (or more) revenue than true supply.

More generally, suppose that $N$ bidders have marginal values of the form $M V\left(q_{i} ; a, b\right)=$ $a-b q_{i}$ where $(a, b)$ is random and the seller has marginal costs $M C(Q)=Q$. Let $p^{\text {resp }}(a, b, N)$ be the unique equilibrium price given adjustable supply which, we know, is on order $\frac{1}{N^{3}}$ less than the Walrasian price $p^{W}(a, b, N)$. Let $p^{*}(a, b, N)$ be an equilibrium 
price given true supply which we know can be as much as on order $\frac{1}{N}$ below $p^{W}(a, b, N)$. Figure 8 summarizes this information, contained in equations (2 4.5$)$.

This leads immediately to the observation that given numerous bidders the seller must strictly prefer adjustable supply unless bidding is close to being as competitive as possible given true supply:

Proposition 2. For sufficiently large $N$, the seller strictly prefers adjustable supply to true supply unless

$$
\operatorname{Pr}_{(a, b)}\left(\lim _{N \rightarrow \infty} N^{3}\left(p^{*}(a, b, N)-p^{W}(a, b, N)=\infty\right)=0\right.
$$

\section{$5 \quad$ Related literature and concluding remarks}

This paper adds the idea of adjustable supply to a various literature on ways to "change the game" of the uniform-price auction without throwing out the uniform-price rule. Given flat demand, adjustable supply eliminates all underpricing equilibria whereas given downward-sloping demand all equilibria must lead to prices on order $\frac{1}{N^{3}}$ below the Walrasian price. The key reason why adjustable supply has this positive effect is that the seller holds out a carrot to the bidders that makes them bid aggressively on the margin. The seller's incentive to increase the quantity sold when announced demand is elastic leads bidders to submit more elastic bids. (See Figure 2, Figure 3, and the discussion surrounding them.)

Other papers have proposed quite different sorts of remedies. When practically feasible, these other ways of modifying the rules can also help sellers to avoid underpricing equilibria in uniform-price auctions. For example, Kremer and Nyborg (2004a) show given flat demand that all underpricing equilibria disappear when a total pro rata tiebreaking rule is used rather than the usual marginal pro rata rule. For example, suppose 
that with two bidders and two hundred units being sold, bidder 1 bids $\$ 20$ for up to 100 units and $\$ 0$ for any more while bidder 2 bids $\$ 10$ for all 200 . The market-clearing price is $\$ 10$ and bidders' total demand at $\$ 10$ is 100 units and 200 units respectively. Given the usual rule, price is $\$ 10$ and each bidder gets 100 units. Under Kremer and Nyborg (2004a)'s rule, price is $\$ 10$, bidder 1 gets 66.7 units, and bidder 2 gets 133.3 units, even though bidder 1 is willing to pay $\$ 20$ for units 66.7-100. McAdams (2002) also tweaks the rules to eliminate all underpricing equilibria. McAdams (2002) gives every bidder who is rationed a portion of a cash prize (or "discount"). Underpricing equilibria disappear no matter how small the discount is. To the best of my knowledge, however, no real-world sellers have or are considering implementing either of these sorts of rules.

In another creative and significant paper, Kremer and Nyborg (2004b) show that underpricing disappears when bidders are restricted to submitting bids that are stepfunctions when these steps may be at any price. More importantly, given discrete quantities and discrete prices, Kremer and Nyborg (2004b) show that the extent of underpricing can be made arbitrarily small when the price tick $\triangle_{P}$ is sufficiently small and the quantity unit size $\triangle_{Q}$ is sufficiently large. In particular, they show that equilibrium prices can be as low as $v-\frac{\triangle_{P}}{\triangle_{Q}}\left(\frac{Q}{N-1}+1\right)$. For fixed $\triangle_{P}, \triangle_{Q}$, however, underpricing can still be on order $\frac{1}{N}$. By contrast, the present paper shows that with adjustable supply underpricing can be on order at most $\frac{1}{N^{3}}$. (This result does not depend crucially on the fact that quantities and prices are continuous nor, in the case of discrete prices and quantities, on the ratio of the price tick to the quantity size.)

Finally, a growing strand of the literature relaxes the assumption that there is a fixed quantity being sold. LiCalzi and Pavan (2005) permit the seller to commit to a supply curve different than true supply and is discussed at more length in Section 3.3. Back and Zender (2001) is perhaps the closest in spirit to the present paper. They assume that the 
seller commits to a "decreasable supply rule". That is to say, the seller commits to reduce the quantity supplied below a pre-specified maximum $\bar{Q}$ if doing so will increase its ex post revenue given the bids. They find that decreasable supply reduces the extent of underpricing while not eliminating it. In particular, equilibrium prices given decreasable

supply can still be on order $\frac{1}{N}$ below the Walrasian price $p^{W}$. Responsive supply differs from decreasable supply in an important way: the seller must be able to increase as well as decrease the quantity sold. This is crucial because the ability to increase quantity is what provides the "carrot" to get bidders to compete more aggressively with each other. When there are discontinuities in the seller's marginal costs this carrot can lose its bite so that adjustable supply becomes more like decreasable supply.

\section{References}

Ausubel, L., And P. Cramton (1998): "Auctioning Securities," Working Paper (Maryland).

BACK, K., And J. Zender (1993): “Auctions of Divisible Goods: On the Rationale for the Treasury Experiment," Review of Financial Studies, 6, 733-764.

- (2001): "Auctions of Divisible Goods with Endogenous Supply," Economics Letters, 73(1), 29-34.

Biais, B., And A. M. Faugeron-Crouzet (2002): "IPO Auctions: English, Dutch, ... French and Internet," Journal of Financial Intermediation, 11(1), 9-36.

Buonnes, G. H. (2001): "Bidder Behavior in Uniform Price Auctions: Evidence from Norwegian Treasury Bond Auctions," Working Paper (Norwegian School of Management). 
Bourjade, S. (2004): "Rationing as a Strategic Tool in Uniform Price Auctions," Working Paper (Toulouse).

Damianov, D. (2004): "Auctions with Endogenous Quantity and the Walrasian Outcome," mimeo (Heidelberg).

Engelbrecht-Wiggans, R., and C. Kahn (1998): "Multi-Unit Auctions with Uniform Prices," Economic Theory, 12(2), 227-258.

Goswami, G., T. Noe, and M. Rebello (1996): "Collusion in Uniform-Price Auction: Experimental Evidence and Implications for Treasury Auctions," Review of Financial Studies, 9(3), 757-785.

Keloharju, M., K. Nyborg, and K. Rydqvist (2004): "Strategic Behavior and Underpricing in Uniform Price Auctions," Journal of Finance, 60(4), 18-65.

Klemperer, P., And M. Meyer (1989): "Supply Function Equilibria in Oligopoly under Uncertainty," Econometrica, 57(6), 1243-1277.

Kremer, I., And N. Nyborg (2004a): "Divisible-Good Auctions: The Role of Allocation Rules," RAND Journal of Economics, 35(1), 147-159.

- (2004b): "Underpricing and Market Power in Uniform Price Auctions," Review of Financial Studies, 17(3), 849-877.

Lengwiler, Y. (1999): "The Multiple Unit Auction with Variable Supply," Economic Theory, 14, 373-392.

LiCalzI, M., And A. Pavan (2005): "Tilting the Supply Schedule to Enhance Competition in Uniform-Price Auctions," European Economic Review, 49(1), 227-250. 
McAdams, D. (2002): "Modifying the Uniform-Price Auction to Eliminate 'CollusiveSeeming Equilibria'," Working Paper (MIT).

Noussair, C. (1994): "Equilibria in a Multi-object Uniform Price Sealed Bid Auction with Multi-unit Demands," Economic Theory, 5, 337-351.

Petruno, T., and A. Pham (2004): "Wall Street May Have Taken Google to School," Los Angeles Times, August 19.

Salant, D., and C. Loxley (2002): "Default Service Auctions," Working Paper (NERA).

Umlauf, S. (1993): "An Empirical Study of the mexican Treasury Bill Auction," Journal of Financial Economics, 33, 313-340.

Wang, J., and J. Zender (2002): "Auctioning Divisible Goods," Economic Theory, 19, 673-705.

Wilson, R. (1979): “Auctions of Shares," Quarterly Journal of Economics, 94, 675-689. 